\title{
Integrated Resources and Training Facilitation - A Strategic Priority When Promoting ICT in Developing Countries
}

\author{
Saifuddin Khalid, Kamrul Islam, \& Tom Nyvang \\ Aalborg University, Denmark
}

\begin{abstract}
In a rural context in a developing country purchasing a computer and connecting it to the Internet is in itself difficult, even when the lack of money is a minor issue. These issues prevent individuals in rural communities from familiarizing themselves with educational technology and ICT in general. The present study investigates the specific barriers to buying and utilizing ICT and ways in which these barriers can be overcome in a case study involving stakeholders from an educational institution in rural Bangladesh. Through a transformative methodology and a phenomenographic approach to the analysis (Larsson \& Holmström, 2007), interview data on the decision-making experience of computer purchases, and the after-purchase experience of learning computer-related skills, the integration of the technology and the skills in interviewees' (students and teachers) learning environments is analyzed. The barriers to purchasing a computer fall in four major categories: Cultural, financial, infrastructural, and knowledge barriers; with knowledge transcending the other barriers. When addressing the barriers to facilitate purchase of a computer locally situated knowledge is crucial. The study concludes that more research is needed to fully understand the diffusion and development of knowledge and inclination to purchase a computer.
\end{abstract}

Keywords: Phenomenography; Educational technology; Barriers to technology; Diffusion of innovations; Promoting ICT; Training facilitation.

\section{Introduction}

It is an under-researched issue that individual learners (i.e. teachers, students and others) are a key source of information about barriers to the adoption and integration of information and communication technology (ICT) in formal schooling, non-formal learning environments (e.g. after-school programs and in-service training), and informal learning environments (e.g. family, peers, neighbors, work, play, telecenters, and mass media) (Cilesiz, 2008), especially as regards to the adoption of ICT in developing countries (Abdullah-Al-Mamun, 2012; Khan, Hasan, \& Clement, 2012; Lashgarara, 2012). Strategies to facilitate the integration and adoption of educational technologies had been focused on educational institutions (Chigona, Chigona, Kausa, \& Kayongo, 2010; Tondeur, van Keer, van Braak, \& Valcke, 2008) and teacher centered (Ertmer, Ottenbreit-Leftwich, Sadik, Sendurur, \& Sendurur, 2012; Ertmer, 1999, 2005). This research studies the barriers through a learner-centered and learning environment-oriented approach; here, every stakeholder in the education system is a learner of ICT. Thus, at an aggregate level, this diffusion research examines how the 'what' and 'how' aspects of the barriers can be addressed through facilitation to teachers and students for purchasing and training on computer and Internet. 
The field of educational technology has been confronting ICT adoption and the integration of barriers for over three decades (Ertmer et al., 2012; Ertmer, 2005; Hew \& Brush, 2006;), at both institutional and individual levels. In the formal learning environment of K-12 education, Hew and Brush's (2006) review of 48 empirical research studies from 1995 to spring 2006 identified 123 barriers and grouped them into six categories; three categories are delineated as teacher-level barriers, with the following relative frequencies, respectively: a) resources (40\%), (b) knowledge and skills (23\%), and (c) attitudes and beliefs (13\%). This research considers the three categories of barriers as individual-level barriers or as educational stakeholders' (i.e. students, parents, teachers, staff, etc.) barriers. Participatory research by Khalid and Nyvang (2013) explained such barriers as micro-level or educational stakeholder's barriers. In addition to the formal learning environment, individuals may also experience these three categories of barriers in the activities of non-formal and informal learning environments (Hussain \& Tongia, 2009; Khan et al., 2012). This research emphasizes that an individual's barriers are typically associated with teachers, educational institutions, and state agencies (Chan, 2011; Ertmer et al., 2012; Ertmer, 1999). In addition, the encounters with barriers situated outside the formal learning environment are largely neglected (Belland 2009). Moreover, definitions of technology integration reflect such neglect. For instance, Belland (2009, p. 354) defines "technology integration as the sustainable and persistent change in the social system of K-12 schools caused by the adoption of technology to help students construct knowledge"; the social system is therefore confined to the formal environment only. This definition does not recognize the uniqueness of each individual's own system of learning, which is constituted of different activities and different learning environments. Therefore, this research suggests that one way to circumvent the barriers of educational technology is to consider stakeholders (i.e. teachers, students, parents, etc.) as the focus of diffusion interventions. Intervention strategies should also consider diverse and prospective learning activities at an aggregate level; that is, in each of the three learning environments.

The ownership of a personal computer, internet access, professional experience, and personal experience play significant roles in the integration of ICT in education (Teo, 2006; Tezci, 2011). In addition, intervention strategies that emphasize distribution of and training in the integration of ICT in educational institutions have resulted in much disappointment, for both the provider and the receivers, because of the lack of technology literacy (Amiel, 2006; Cuban et al., 2001). Moreover, while ownership and technology literacy in the developed countries are high, the developing countries are lagging far behind, particularly Bangladesh (Abdullah-AlMamun, 2012; Ertmer et al., 2012; Hussain \& Tongia, 2009).

The present study addresses the individual educational-stakeholder's barriers to ICT adoption and integration in education by focusing on barriers to ownership of a computer and Internet connectivity, and approaches to circumventing these barriers. Thus, this study is situated in a technical vocational education and training (TVET) institution in rural Bangladesh, where the first author played the role of change agent (Rogers, 1995) to facilitate the adoption and integration of computers and Internet in the learning environments of teachers and students. "A change agent is an individual who influences client's innovation decisions in a direction deemed desirable by a change agency" (Rogers, 1995, p.336). Amidst diverse barriers in Bangladesh (Khalid \& Nyvang, 2013; Khan et al., 2012), the change agent facilitated the purchase of laptops and accessories by interest-free installments, on-site after-purchase training, and additional facilitation during two field studies conducted in 2011 and 2012, totaling 7 months. 
To uncover and unfold individual level-barriers to educational technology; specifically barriers to ownership of a computer and Internet connectivity, and approaches to circumventing these barriers, this article begins with a review of known individual level barriers to educational technology in a development context. Then, it moves on to presenting the methodology, analysis, discussion, recommendations, and conclusion.

\section{Individual-Level Barriers to the Adoption and Integration of Educational Technology}

This section reviews the barriers to educational technology at the individual level. This review is called the 'bracketing' method (Ashworth \& Lucas, 2000), which pre-supposes the 'categories of description' of phenomenographic analysis. In addition, the following review discusses the motivation behind situating the case (i.e. a vocational education institution from a rural area) and the embedded units (i.e. teachers and students) of this study in rural Bangladesh.

In educational technology literature, the terms 'adoption' and 'integration' are defined with significant similarity, and the difference is lacking clarity (Belland, 2009). This research employs 'adoption' as the decision-making process (Rogers, 1995) of the purchase and purposefullearning of a computer and Internet technologies; 'integration', on the other hand, refers to the appropriation of technological skills in the 'learning activities' (Tondeur et al., 2008; Wachira \& Keengwe, 2010).

This study builds on the review paper by Hew and Brush (2006). Thus, following a discussion on barriers at the individual or micro level (i.e. resources, knowledge and skills, attitudes and beliefs, and subject culture), the intervention strategy of this research is elaborated as follows. The lack of resources is classified as: (a) technology, (b) access to available technology, (c) time, and (d) technical support. A fifth sub-category of resource is funding (Hew \& Brush, 2006; Rogers, 2000). Knowledge and skills can be categorized as: (a) lack of specific technology knowledge and skills, (b) technology-supported pedagogical knowledge and skills, (c) technology-related-classroom management knowledge and skills. Hew and Brush (2006) also found that teachers' belief may include their educational 'beliefs about teaching and learning' (i.e. pedagogical beliefs), and their 'beliefs about technology' (Ertmer, 2005); beliefs also determine a 'person's attitude' (cited Bodur, Brinberg, \& Coupey, 2000). The intervention strategy of this research attempted to address the resource barriers of technology and the access to available technology by providing purchase facilitation. In addition, the barrier of the lack of specific technology knowledge and skills and technology-supported pedagogical knowledge and skills was addressed through learning-environment focused, problem-oriented and within-institution training. The phenomenographic analysis identifies the experience of this intervention, which results in the identification of other associated barriers, which provides greater insight into clients' experiences and future considerations for the change agents and agencies.

The barriers are far more severe among the disadvantaged educational contexts of the developing countries, mainly in their rural areas (Abdullah-Al-Mamun, 2012; Hussain \& Tongia, 2009; Kessy et al., 2006; Khan et al., 2012; Lashgarara, 2012; Sharma, 2003). Most importantly, about $70 \%$ of the world's poor people are living in disadvantaged rural areas which deserve greater attention (World Bank, 2012). Moreover, the developing countries of the Asia Pacific region increased the emphasis on 'ICT in education' (Akhtar \& Arinto, 2009). Conceivably, the most notable among them is the "Vision 2021: Digital Bangladesh" (A2I: PMO, 2009; BOI: PMO, 
2009), which focuses on six areas of ICT in education: General and TVET education systems, the professional development of teachers using ICT, education-related citizen services, ICT literacy for students, ICT infrastructure and delivery channels, and ICT in the educational administration (A2I: PMO, 2009). Thus, the purchase of computers and the training facilitation for teachers and students in a rural TVET institution in Bangladesh will offer a contribution to both the national and the international agendas.

Bangladesh has a population of 142 million people (BBS, 2011) and $72 \%$ of its inhabitants live in rural areas (World Bank, 2012). Over 91\% (2730 of 2981) of the TVE institutions of Bangladesh are private, and these host about $80 \%$ of teachers and more than $70 \%$ of students of the technical education (BANBEIS, 2012). In addition, more than $55 \%$ of the TVE institutions are located in the rural areas (BANBEIS, 2011). This research draws attention to the underresearched field of private TVET institutions and the rural secondary and higher secondary institutions in Bangladesh.

The public polytechnic institutions of Bangladesh are facing significant barriers to providing computer and Internet services: according to teachers' responses in a recent study, these barriers are lack of technology (55\%), training (55\%), knowledge (38\%), skills (32\%); administrators pointed at high expenditure (69\%), lack of skilled personnel (47\%), students and teachers prefer the traditional method (53\%) (Abdullah-Al-Mamun, 2012). The opinion of the administrative decision makers indicates that the adoption and integration of ICT might be farreaching. Because the administrators usually prefer traditional methods, considering ICT adoption as a high expenditure issue, and struggling to find ICT-skilled personnel, institutionled authoritative decision to adopt (Rogers, 1995, p.207) is fundamentally restricted. Therefore, this research explored the potential of the agent-facilitated optional or collective innovation-decision (Rogers, 1995, p.207) at the individual level, i.e. among educational stakeholders.

\section{Methods}

In the preparation phase of the present study we found ourselves to be in a difficult situation. With an interest in studying barriers to purchasing computers for learning purposes in a rural area of a developing country we faced three major problems: (1) We didn't have access to any useful cases to study; (2) Not being truly familiar with rural areas of a developing country we expected to have great difficulties in asking the right questions even if we had found a case; and (3) Our purpose was not only knowledge but if possible we would also induce change. We found a way to meet those challenges in the transformative paradigm. Transformative researchers "believe that inquiry needs to be intertwined with politics and a political agenda" (Creswell, 2003, p.9) and should include an action plan for change "that may change the lives of the participants, the institutions in which individuals work or live, and the researcher's life" (Creswell, 2003, p.9).

This paradigm argues for participatory methodology and mixed-method approaches for the development of "more complete and full portraits of our social world through the use of multiple perspectives and lenses" (Somekh \& Lewin, 2005, p.275). It does so to gain an understanding of "greater diversity of values, stances and positions" (Somekh \& Lewin, 2005, p. 275). 
The transformative paradigm encouraged us to play an active role in creating a case to study, thus inducing change. It told us that a participatory approach would engage us in a learning process together with locals situated in a rural area; thus, helping us to build a shared vocabulary and mutual understanding of the barriers.

The transformative paradigm does not generally begin with a theory but "generate or inductively develop a theory or pattern of meanings" (Creswell, 2003, p.9) during the research process. However, unlike other paradigms, transformative research emphasizes social justice and marginalized people (Creswell, 2003, p.9).

\section{Data Collection}

This research was designed as a single-case study with embedded units (i.e. teachers and students) (Stake, 1995) and was situated in a private, vocational, and rural TVET institution in Bangladesh. The purchase and training facilitation recipients, 6 teachers and 2 students (see Table 1), were interviewed during the second field study face-to-face in Bangladesh end reinterviewed a year later over Skype-to-mobile to follow up on the purchasing experience. The interviewees were those who didn't own a computer but expressed the firmest interest in purchasing one. Our data are thus biased towards a positive attitude towards computers from the beginning which we will of course keep mind when discussing the results of the study.

Table 1. Recipients of Facilitation and Participants of Interview

\begin{tabular}{|c|l|l|l|}
\hline Units & $\begin{array}{l}\text { Designation } \\
\text { (in 2011) }\end{array}$ & Degree & Subject/Discipline \\
\hline Teacher 1 & Principal & M.Sc., B.Ed. & Statistics \\
\hline Teacher 2 & Lecturer & M.Com. & Accounting \\
\hline Teacher 3 & Lecturer & M.A. & Bangla \\
\hline Teacher 4 & Assistant Teacher & M.A., B.Ed. & English \\
\hline Teacher 5 & Assistant Teacher & B.Sc., B.Ed. & Mathematics \\
\hline Teacher 6 & Trade Instructor & $\begin{array}{l}\text { Diploma in Electrical } \\
\text { Engineering }\end{array}$ & $\begin{array}{l}\text { General electrical } \\
\text { works }\end{array}$ \\
\hline Student 1 & $12^{\text {th }}$ grade, graduated & S.S.C. Voc, Computer & HSC BM, Computer \\
\hline Student 2 & $\begin{array}{l}12^{\text {th }} \text { grade, Enrolled in } \\
\text { undergrad, Accounting }\end{array}$ & $\begin{array}{l}\text { S.S.C. Voc, Computer } \\
\text { HSC } \\
\text { Accounting }\end{array}$ \\
\hline
\end{tabular}

\section{Data Analysis}

This research study is positioned within the category of "experimental phenomenography" (Hasselgren \& Beach, 1997) and the transcribed text is analyzed by application of the phenomenographic methodology (Larsson \& Holmström, 2007; Marton, 1981, 1997) as follows.

1. Read the whole text.

2. Read again and mark where the interviewee gave answers to the main interview questions. 
3. In these passages, look for what the focus of the interviewee's (i.e. student's or teacher's) attention is and how she/he describes her/his way of deciding or doing. Make a preliminary description of each teacher's and student's predominant way of experiencing the phenomenon.

4. Group the descriptions into categories based on similarities and differences. Formulate categories of description.

5. Look for non-dominant ways of understanding.

6. Find a structure in the outcome space.

7. Assign a metaphor to each category of description.

Interview transcription is practiced in different ways, among which this study uses denaturalism, "in which grammar is corrected, interview noise (e.g., stutters, pauses, etc.) is removed and non-standard accents (i.e., non-majority) are standardized" (Oliver, Serovich, \& Mason, 2005, p.1273). In this way, the transcription process involved two phases. First, two of the authors transcribed and translated the interviews from Bengali to English. Secondly, a professional English language expert was consulted for the carefully selected text from the transcriptions.

The first author conducted the field studies and interviews; other authors contributed to translation, transcription and methodological analysis. The term 'researcher' within the quoted texts of the transcription and the term 'change agent' elsewhere refer to the first author. The term 'client' refers to the targeted stakeholders of the institution and the interviewees.

\section{Results}

The phenomenographic analysis of the interviews displayed variations and similarities among the interviewees' experiences. The participant observation by the change agent contributed significantly in conducting and analyzing the interviews with sufficient empathy, which is recommended by Ashworth and Lucas (2000). In addition, the change agent's live-in field experiences contributed in validating and verifying the responses. The change agent lived, worked, trained, and shared experiences with the school community. The agent's experiences within the interviewees' households, the institution, and elsewhere provided opportunities to verify the reflections in the interviews. In some cases, the interviewees' reflections were overstatements of their actual practice or achievements. In such cases, the change agent (i.e. interviewer) validated the claim by re-questioning the interviewee to reflect the actual experience. After the analysis, the selected quotes from the interviews and the categorization of the descriptions were verified with the participants. Considering the convenience of the interviewees, this verification was conducted through emails and mobile discussions. This section analyzes the experiences of the interviewees in each of the three phases of the broad phenomenon. In addition, the experiences of the barriers (i.e. 'what') and the circumvention of the barriers (i.e. 'how') are described to unfold the ICT adoption barriers.

\section{The Experience of Barriers to Purchase Computer and Internet Technologies}

In the first phase of the study of the broad phenomenon of individuals' adoption and integration processes the participants responded to two main questions: (1) What barriers had 
been preventing your decision to purchase or the purchase of a computer and Internet technologies (Barrier 1-25 in the analysis)? (2) How did you overcome these barriers and acquire the computer resources (Strategy 1-23 in the analysis)? The responses to the 'what' question resulted in the categories of barriers which were pre-supposed through the bracketing method. The answers to 'how' questions are the related intervention experiences that solved or circumvented the barriers.

\section{Lack of Specific Technology Knowledge and Skills}

Barrier 1 \& 2: Lack of knowledge about the features and quality of technology; Lack of knowledge about reliable markets/shops to purchase from. Each of the interviewees mentioned these two barriers. These barriers are related to both the decision to purchase (Teacher 3) and the actual purchase (Student 2).

Teacher 3: Which type [desktop/laptop] of computer should I buy? From where should I buy? Which brand should I buy? If I go to buy, since I do not know much about computers, then if it is good or bad, if it is suitable for me - even determining these would have been a problem.

Student 2: I did not have enough knowledge on the quality of computers (which brand and what functions I should ask or look for), the price and if the seller is reputed as a reliable seller and service provider.Although I had visited a computer fair in Dhaka [city] and I also visited some shops where I considered purchasing a desktop, I could not decide and could not tell my father about the purchase.

Strategy 1 \& 2: Each of the interviewees mentioned that the training, workshops, and discussions were persuasive; most importantly, the change agent's knowledge and sourcing of the technology were reliable.

Teacher 3: When you discussed with us and told us that you are ready to help us, then without hesitation I left these decisions on your shoulders.

Student 2: Later, when you arrived, I discussed with you and I was convinced that in the given electricity condition and other flexibilities, I should purchase a laptop instead.

Barrier 3: Lack of knowledge about how to use a computer and for which purposes. Except Teacher 1, all other interviewees mentioned that their previous knowledge about how to use a computer had been theoretical and their previous hands-on experiences were not related to purposeful activity in real life.

Teacher 2: Previously I knew a little bit of computer use. But I did not know how to use the Internet and how the Internet can be useful

Teacher 3: In fact, a computer is a useful device - this I knew before. But in reality, we did not know what we should do after buying a computer.

Strategy 3: Training, problem-based learning and purpose-oriented activities with computer and Internet with the change agent were described to explain how these experiences persuaded the decision to purchase. 
Student 1: Mainly, I was eager to know how everyone and I can talk face-to-face with my brother and sister, who are staying abroad. I did not think that anyone else but you can do it. For example, when I talked using your mobile, over Skype, at that time I became more eager. Maybe if a laptop is bought for me [by brother and sister] and if you create an account for me, I shall be able to do it [use Skype] on my own.

\section{Attitudes and Beliefs}

Barrier 4 \& Strategy 4: Lack of technology know-how led to lack of inspiration. The participants' expression was translated as 'inspiration', which refers to internal spirit. Apart from Student 1, other participants mentioned this barrier and related it to the decision to purchase.

Student 1: Previously, I did not even have the opportunity to know about computers. I learned a little from ninth and tenth grades, as I studied with computer trade...Later, from college [eleventh and twelfth grades] I started feeling that I can use a computer. After learning many more ways of using a computer and the Internet from your training, I got inspiration to buy.

Teacher 4: One doesn't become eager to do something if one doesn't learn it, isn't it? So, when you showed us how to use it, persuaded us, taught us how to use it, how it can be used and we saw the usefulness, then we thought about buying it.

Barrier 5 \& Strategy 5: Lack of trust in vendors. Each of the interviewees believes that there is very high chance that a buyer of an IT product will be swindled if $s /$ he lacks confidence and the ability to evaluate product quality, product price and the vendor's reputation. The change agent's expertise was deemed to be sufficient.

Teacher 2: "We do not have much knowledge about computers and the quality of computers. I had the possibility to be cheated or swindled. Since you are a computer knowhow person, if I purchase through you, there is no chance to be cheated or swindled. Otherwise I might end up with a low-quality product with a high price, and typically they behave very badly if we go for any kind of support in the future."

Barrier 6 \& Strategy 6: Purchasing a product from a foreign country is more reliable. While distrust in the native vendor is reflected by each adopter, two $(\mathrm{S} 1, \mathrm{~T} 6)$ of them had family members staying abroad who facilitated the purchase of laptops.

Teacher 6: I had the opportunity to purchase from a foreign country. I thought it would be a better quality than buying from Bangladesh.

Barrier 7 \& Strategy 7: Lack of motivation. Each of the participants identified this as one of the major barriers and related it to the purchase decision. The term 'motivation' refers to external persuasion or a push.

Student 1: I had a plan to buy but I was motivated when you [change agent] trained us, showed us how to use laptops for various purposes and suggested us to buy one. I thought 
that I can ask my brother and sister, who are staying abroad, to send a laptop. With my own computer I shall be able to learn more from you.

Teacher 6: Most importantly, no one motivated me to purchase a computer. So, I promptly decided when you asked us to purchase a laptop instead of a desktop, which can support up to three hours of power backup during power outage, it is handy and I can carry it along. I always had the ability to purchase a computer but I just needed sufficient motivation. I was motivated by the persuasive discussions with you.

Barrier 8 \& Strategy 8: Fear. The word 'fear' was used as fear of destroying or causing malfunction of the expensive device, getting stolen, afraid of the device remaining unused due to lack of time.

Teacher 5: I have many classes in the institution and I remain very busy. If I purchase, I was afraid I shall not be able to give enough time to learn and to use the computer...I got courage from you [change agent].

Teacher 1: You assured us that if we do not drop it in the water or throw it, then usually it does not get non-operational or damaged ['nosto' in Bengali].

Barrier 9 \& Strategy 9: Prevailing distrust in the society. The acceptability of a change agent depends on the community and its members' inter-personal trust relationships. The change agent's (i.e. researcher's) ability to persuade depends on her/his socio-political status among the clients (i.e. teachers and students).

Teacher 5: I would not have believed anyone else [if offered similar facilities]. You are in a project in our institution and you are in connection with the founder [of the institution]. That is why we purchase through you. If anyone else had told us, I/we might not have bought.

In case I had felt such a need, from others than you [someone other than the agent], I would have also consulted with those who knew [about computers]. I would have shared [my plan to purchase] with them. I would have purchased after trust- building, which might have delayed that decision. It would have taken more time to decide.

\section{Resources}

Barrier 10 \& Strategy 10: Lack of electricity. As this barrier fundamentally prevents the decision to purchase an electricity dependent technology item, the interviewees' related this to the purchase decision and choosing between a desktop and a laptop.

Teacher 1: Your [the change agent's] idea of buying a laptop instead of a desktop was appropriate for us, because we can work even when there is no electricity.

Barrier 11 \& Strategy 11: Lack of support services. This barrier might prevent the decision to purchase. However, the availability of convenient and informal support for basic troubleshooting might circumvent this barrier. 
Student 1: I did not have opportunities to know if anything goes wrong with a laptop or a computer. Since you are here and others also have learned, I can get help now.

Barrier 12 \& Strategy 12: Weak Mobile network connectivity. Each respondent identified this as a major barrier, which results in unreliable Internet connectivity. The connection strength varies within different locations of the same household's space.

Teacher 1: Because of mobile network disturbance I am now sitting in my courtyard to talk to you [for the interview].

Barrier 13 \& Strategy 13: Lack of trainer to teach desired skills. Despite curiosity to know the use of computers and the Internet, there was little opportunity to learn the desired skills. Each of the participants considered this to be a barrier to the purchase decision. The respondents considered the anticipated future training and facilitation from the change agent as methods by which to circumvent this barrier (e.g. Teacher 6 ).

Student 2: I went to Dhaka to learn computer but even there they did not teach me so many things as you [change agent] did [before the purchase decision]. They only taught me how to do typing. But you were teaching some skills. If I have my own computer, I shall be able to practice at home and I shall be able to remember this. That would also boost my interest.

Teacher 6: Twice I had saved money to a buy computer, but then I thought who is going to teach me how to use it, and what benefits am I going to get from it? So, later I spent my savings for other purposes..... thought that if I buy now, I shall be able to get training from you. I can get help when I face a problem and if I want to learn something new.

Barrier 14 \& Strategy 14: Lack of time. Professional workload leaves little time for learning and integrating new technology. The interviewees did not mention 'how' this barrier was addressed.

Teacher 1: The institutional workload [for teachers] is very high. So, we will have to allocate time. But we were convinced that if we buy, it will save our time and will ease our tasks.

Teacher 5: I have many classes in the institution and I remain very busy. If I purchase, I was afraid if I shall be able to give enough time to learn and to use the computer.

\section{Lack of Financial Strength}

Barrier 15 \& Strategy 15: Income level is far too low to purchase at one instance. Except Student 2, other recipients of the instalment facility mentioned this as a major barrier.

Teacher 5: I did not have enough money. It would have been tough to buy with full payment. The instalment process was convenient.

Teacher 3: It was difficult for us to purchase at once with our salary. Such difficulty is faced by all those of us who bought a computer. We received the computer at hand by paying a relatively small amount as the down payment. So, it was easy for us to purchase. 


\section{Subject Culture}

Barrier 16 \& Strategy 16: Subject culture and folk pedagogies that limit the use of technology. The traditional folk pedagogies of teaching which a teacher experienced as a student or a student teacher, shape the attitudes and beliefs of a teacher (Belland, 2009). A subject culture or the way to teach a subject can be defined by the practices in a school or by an individual teacher. Teacher 2, Teacher 3, Teacher 4, and Teacher 5 mentioned similar barriers among the teachers. The change occurred through observation, trial and interaction with the change agent.

Teacher 2: As an accounting teacher I used to think that I do not need to have these [computer and Internet] rather these are only for computer people.

After your arrival when you showed me the use of the Internet through a mobile phone, helped me creating emails and a Facebook account in my mobile, showed me how to search in Google, read newspapers etc., I tried myself and found that I can find much information from the web. But when I tried to download some content or even read a newspaper, it gives the message 'insufficient memory'. I realized that a mobile will not be sufficient, I need a laptop. I felt that a computer is required for any individual and not just people with specific tasks.

\section{The After-Purchase Experience of Learning to Use the Computer and Internet Technologies}

Each of the participants mentioned similar experience in response to the questions "what skills did you learn after the purchase of computer and Internet technologies?" and "how did you learn?"

Barrier 17: Use of the Computer: Recognizing indicators and external parts of the laptop, controlling the mouse and painting by the use of paint software, handling files and folders, transferring data by using flash drives and CDs, editing images, using Microsoft Word and Excel, English typing, Bangla (Bengali) typing by using Avro phonetic keyboard software, Bijoy keyboard software, listening to music and watching video content, using multimedia content for teaching in the classroom and for children.

Barrier 18: Use of Internet: Connecting a modem, subscribing to an Internet package, browsing and searching by using three different browsers; operating web-based applications for educational administration;reading newspapers, listening to the radio from websites, downloading files, searching and applying for jobs through job portals; using email,Facebook, and Skype.

Every interviewee mentioned within-institutiontraining workshops and problem-based facilitation with the change agent. In addition, the known experts within the institution provided skills to one another through cooperation, observation and problem solving.

Teacher 1: Although I learnt to use a computer from previous training and I could type some essential documents using office applications, I learned more during your training workshops at the institution and during various situations of problems and the facilities of 
the computer and Internet ...sometimes from Rajib [ad-hoc teacher cum office assistant], who learned the most among us from you [change agent].

\section{Integration of the Technologies and Skills in the Learning Environments}

The analysis of this third phase of the intervention involved responses to two main questions. These were: (1) In what activities of your learning environments did you use your computer and Internet technologies and related skills you gained? and (2) How did you experience your technologies and your skills for those learning activities? Responses to the 'what' question are analyzed to identify categories of activities. Responses to the "how" question offered qualitative insight into participants' integration of technologies in their learning activities and the changes in their attitudes and beliefs.

\section{Barrier 19 \& Strategy 17: Classroom activity}

Teacher 2: In the absence of an English teacher, the contents of the smart classroom that he/she is supposed to teach, I could teach those in the English classes only because I have a computer and I have those contents in my computer. I could practice those at home. I did not get any training from the NGO and got the training from you [change agent]. Since I gained some courage and skills, I took the initiative to teach those....

\section{Barrier 20 \& Strategy 18: Preparation for class and self-study}

Teacher 2: Previously I did not have the ability to use accounting lesson content in a typed and printed form. After my purchase, I gained the ability to do that.

Student 2: I use two [software] dictionaries [English-Bengali] for mathematics, because my mathematics book is in English.... It takes less time to search from a computer dictionary than from a paper dictionary.

Barrier 21 \& Strategy 19: Educational administration. Since mid-2011, the TVET board of Bangladesh has enforced the use of the Internet for educational administrative activities with each institution, which includes curricula, regulations, and notices, annual planning, class scheduling, curriculum content, syllabus, admission, registration, assessment and evaluation. Until this purchase and training facilitation, the institution was dependent on external services for Internet-dependent administrative information and activities.

Teacher 1: Yesterday, at quarter to one [at noon] a student rang me that class nine's result was published [in education board's website]. I called up Rajib [ad-hoc teacher cum office assistant] but both of his [mobile] numbers were unreachable. Although this result cannot be accessed by mobile, the young students became excited about it [result] and tried getting it by mobile. After the prayer I sat down with my laptop. .... At 10-11 at night I promptly gave the results to all the students who inquired. ...it did not take even five minutes. ...this saved money and time; I did not have to worry about a person [whom to send to publish the information otherwise] and the probable dissatisfaction of inquiring students. Now, every one or two alternative days I search relevant websites for important information of the board and the directorate. ... Recently, I have also been getting some important [official] emails. ... On the 19th of this month [Feb 2013] at quarter to nine at night, DG's [Director General of TVET board] approval of five of our newly-appointed teachers' MPO [monthly payment order] was published as part of a list. ... I rang each of 
the teachers to tell them that their MPO had been approved ... I also informed other teachers from other institutions in Nabinagar [area]; ....

Teacher 2: As I am the ICT committee convener, the principal asked me to assist Rajib for marks entry to the BTEB website. I have done part of the form filling and submission, and I supervised the task. I also found some errors and helped in correcting those. ...... I found my own promotion and seniority from the website ... ... and I could inform the principal.

\section{Barrier 22 \& Strategy 20: Learning and social networking through Facebook}

Teacher 2: Through Facebook sharing I could learn many things. One of my friends shared one piece of Islamic information about prayer. I could learn that. I try to follow that. I also shared that. Similarly, I learn much information and share this. For example, I could not watch games on my TV and other news, but I could follow recent news and updates, which I also shared on Facebook. ... My alumni association could not reach me over the mobile, and they informed me over email. I could attend that reunion because I had my own laptop and Internet. ... I also uploaded some pictures [on Facebook] and I could share these with my students, [who are living] in various places [countries]. I could also chat and share mobile numbers with them.

\section{Barrier 23 \& Strategy 21: Internet-mediated access to newspapers}

Teacher 3: In our village we do not get the newspaper delivered within that day. We get newspapers after one day. So, if I sit with my computer, I can get the newspaper immediately.

\section{Barrier 24 \& Strategy 22: Learning and communication opportunities for family and society}

Teacher 2: One of my friends is staying in the UK. He forgot my number and he could not contact me. He emailed me and luckily I was in Dhaka and I could meet him. Without email I could not have met him after many years. It's because he knew my email address. I had once informed him about my email address when he called me from UK.

Student 2: I can talk [with cousins] on Facebook, that's why I do not have to use email. From your [change agent] multimedia content for teaching English, my child got some benefits. For example, in the content, there is a game on the appropriate use of articles and numbers. My kid is not supposed to know that. As part of the game he practiced those. At the age of 7 I did not expect him to learn these so quickly, but he did. I believe it is because of the computer and the content.

Barrier 25 \& Strategy 23: Engaging Children in learning activities. Five of the six teachers mentioned that the children in the family enjoy watching multimedia learning content.

Teacher 1: Today, for example, is Friday right [emphasizing weekly holiday]. This morning I told my two young daughters that I shall play with them and show them the computer. I showed them the computer for an hour, and I could keep them engaged at home till now. They saw Sisimpur [Bengali UNESCO program like Sesame Street] and rhymes, the rhymes about alphabets. Showing these, I could keep them at home. Otherwise, they do not want to stay at home. 


\section{Discussion and Recommendations}

The present study set out to uncover and unfold individual level-barriers to educational technology; specifically barriers to ownership of a computer and Internet connectivity, and approaches to circumventing these barriers.

During the analysis it has been shown that barriers and corresponding strategies to circumvent them fall in 7 categories:

1. Lack of specific technology knowledge and skills

2. Attitudes and beliefs

3. Resources

4. Lack of financial strength

5. Subject culture

6. The after-purchase experience of learning to use the computer and Internet technologies

7. Integration of the technologies and skills in the learning environments

All the seven categories of barriers and strategies are related to culture (most prominently 2, 5,7 ), financial strength (most prominently 3,4 ), infrastructure $(3,6,7)$ and knowledge (most prominently $1,6,7)$.

Culture is culture within subjects (what is important and how do we teach it?) and culture within the local community and probably greater areas of rural Bangladesh (those who want to purchase a computer often cannot find anyone they trust to take advice or purchase from). It appears that even if it is traits of the culture we are looking at lack of knowledge is a common denominator too. What the community really lacks is one or a few experts on educational technology and sufficient knowledge spread in the rest of the community so that the experts are acknowledged as experts. In the present study local innovators trusted the change agent sufficiently to let him assist them to purchase a computer. Thus, it can be recommended that change agents stay long enough in a rural community to induce a change in culture through dissemination of knowledge. More research is needed before one can say how long a change agent needs to be part of the community for a sustainable change in the culture to take place. More research is also needed to find out how to persuade other than innovators to purchase computers.

Financial strength is another great barrier to ICT and educational technology. In the present study money from outside has helped the school to purchase some ICT but sufficient scaffolding from the change agent also released local money for purchase of ICT. It is possible that more locally accepted knowledge will release more local money for further funding of ICT and educational technology. A barrier within the financial strength barrier is the fear of breaking something because it cannot be replaced. The fear of breaking something appears to prevent local knowledge development because no one dares to experiment and learn by trial and error. It can be recommended that future development initiatives supports local investment in educational technology and ICT in general but further research is needed for a 
sustainable business model of a funding scheme to be developed. In Bangladesh micro-funding is known but at the moment it doesn't extent into educational technology.

The infrastructure barriers are the ones that are the most difficult the deal with locally. It is difficult (and sometimes dangerous) to travel to an urban area for purchase of ICT and back to a rural community. Another infrastructural issue is the lack of good Internet connections. The authors have no solid recommendations to offer here. Arguing for better infrastructure is easy but the funding is difficult. Thus, one can recommend more research into sustainable models of infrastructures, specifically Internet, for rural areas in developing countries.

Knowledge is important for educational technology to succeed. This study has shown that a change agent can disseminate knowledge and start a positive trend towards local knowledge development with regards to educational technology and ICT in a broader sense. On-site training before purchase offers opportunities for observability, trialibility and relative advantage for the innovation (i.e. ICT in education) adoption decision (Rogers, 1995, p.207); training and facilitation after purchase enables the problem-based and learning environmentoriented integration of ICT. In the present study the main focus is barriers and circumventing barriers to purchase of computers and already at this level that to a typical European appears very basic; it is almost not worth devoting attention to a lack of knowledge is a barrier to educational technology. This leaves us with the recommendation that much more attention is devoted to disseminating basic knowledge on computers so that individuals within the local community will feel to be able to take active part in purchasing decisions. More research is needed before we fully understand the importance of rural knowledge and rural knowledge development when it comes to educational technology and the different components of a purchasing decision.

\section{References}

A2I: PMO. (2009). Strategic priorities of digital Bangladesh: Improving education sector. Access to Information, Prime Minister's Office, Bangladesh. Retrieved on 19 May 2012 from http://www.digitalbangladesh.gov.bd/documents/Education.pdf

Abdullah-Al-Mamun, M. (2012). Technology in Educational Settings in the Government Polytechnic Institutes of Bangladesh: A Critical Analysis. International Journal of Computer Applications, 54(13). Retrieved on 19 May 2012 from http://research. ijcaonline.org/volume54/number13/pxc3882502.pdf

Aduwa-Ogiegbaen, S. E., \& lyamu, E. O. S. (2005). Using information and communication technology in secondary schools in Nigeria: Problems and prospects. Educational Technology \& Society, 8(1), 104-112.

Akhtar, S., \& Arinto, P. (Eds.). (2009). Digital Review of Asia Pacific, 2009-2010. Delhi: SAGE Publications. Retrieved on 19 May 2012 from http://site.ebrary.com/id/10314695

Amiel, T. (2006). Mistaking Computers for Technology: Technology Literacy and the Digital Divide. Association for the Advancement of Computing In Education Journal, 14(3), 235256.

Ashworth, P., \& Lucas, U. (2000). Achieving Empathy and Engagement: A practical approach to the design, conduct and reporting of phenomenographic research. Studies in Higher Education, 25(3), 295-308. doi:10.1080/713696153 
BANBEIS. (2011, August 27). Number of Technical Institution, Teacher and Enrolment by Location. Bangladesh Bureau of Educational Information and Statistics. Government of Bangladesh. Retrieved on 29 February 2012 from http://www.banbeis.gov.bd/webnew/ index.php?option=com_content $\&$ view=article \&id $=456$ : number-of-institution-teacherand-enrolment-by-location\&catid=77:technical-and-vocational-education2010\&ltemid $=185$

BANBEIS. (2012). Number of Vocational Institution, Teacher and Enrolment by type, management and sex - 2011. Bangladesh Bureau of Educational Information and Statistics. Government of Bangladesh. Retrieved on 29 February 2012 from http://www.banbeis.gov.bd/webnew/index.php?option=com_content\&view=article\&id =628:table-65-number-of-institution-teacher-and-enrolment-by-type-management-andsex2011\&catid=99:technical-and-vocational-education-2011\&/temid=202

BBS. (2011, July). 2011 Population \& Housing Census: Preliminary Results. Bangladesh Bureau of Statistics. Government Official. Retrieved on 22 February 2012 from http://www.bbs. gov.bd/WebTestApplication/userfiles/Image/Census2011/Bangladesh_glance.pdf

Belland, B. R. (2009). Using the theory of habitus to move beyond the study of barriers to technology integration. Computers \& Education, 52(2), 353-364. doi:10.1016/j.compedu.2008.09.004

BOI: PMO. (2009). Government Vision 2021. Board of Investment, Prime Minster's Office, Bangladesh. Government of Bangladesh. Retrieved on 19 May 2012 from http://boi.gov.bd/about-bangladesh/government-and-policies/government-vision-2021

Chan, C. K. K. (2011). Bridging research and practice: Implementing and sustaining knowledge building in Hong Kong classrooms. International Journal of Computer-Supported Collaborative Learning, 6(2), 147-186. doi:10.1007/s11412-011-9121-0

Chigona, A., Chigona, W., Kausa, M., \& Kayongo, P. (2010). An emperical survey on domestication of ICT in schools in disadvantaged communities in South Africa. International Journal of Education and Development Using Information and Communication Technology, 6(2).

Cilesiz, S. (2008). Educational computer use in leisure contexts: A phenomenological study of adolescents' experiences at internet cafes. American Educational Research Journal, 46(1), 232-274. doi:10.3102/0002831208323938

Creswell, J. W. (2003). Research design: Qualitative, quantitative, and mixed methods approaches. (2nd ed.). Thousand Oaks, NJ: Sage.

Cuban, L., Kirkpatrick, H., \& Peck, C. (2001). High Access and Low Use of Technologies in High School Classrooms: Explaining an Apparent Paradox. American Educational Research Journal, 38(4), 813-834. doi:10.3102/00028312038004813

Ertmer, P. A. (1999). Addressing first- and second-order barriers to change: Strategies for technology integration. Educational Technology Research and Development, 47(4), 4761. doi:10.1007/BF02299597

Ertmer, P. A. (2005). Teacher pedagogical beliefs: The final frontier in our quest for technology integration? Educational Technology Research and Development, 53(4), 25-39. doi:10.1007/BF02504683 
Ertmer, P. A., Ottenbreit-Leftwich, A. T., Sadik, O., Sendurur, E., \& Sendurur, P. (2012). Teacher beliefs and technology integration practices: A critical relationship. Computers \& Education, 59(2), 423-435. doi:10.1016/j.compedu.2012.02.001

Hart, C. (1998). Doing a literature review : releasing the social science research imagination. London: Sage.

Hasselgren, B., \& Beach, D. (1997). Phenomenography - a "good-for-nothing brother" of phenomenology? Outline of an analysis. Higher Education Research \& Development, 16(2), 191-202. doi:10.1080/0729436970160206

Hew, K. F., \& Brush, T. (2006). Integrating technology into K-12 teaching and learning: current knowledge gaps and recommendations for future research. Educational Technology Research and Development, 55(3), 223-252. doi:10.1007/s11423-006-9022-5

Hussain, F., \& Tongia, R. (2009). Cross technology comparison for information services in rural Bangladesh (pp. 252-266). IEEE. doi:10.1109/ICTD.2009.5426676

Kessy, D., Kaemba, M., \& Gachoka, M. (2006). The reasons for under use of ICT in education: in the context of Kenya,Tanzania and Zambia. Presented at the Technology for Education in Developing Countries (pp. 83-87). Fourth IEEE International Workshop on IEEE. doi:10.1109/TEDC.2006.31

Khalid, M. S., \& Nyvang, T. (2013). Application of Participatory Learning and Action Methods in Educational Technology Research A Rural Bangladeshi Case. In M. Georgsen \& P.-O. M. Zander (Eds.), Changing Education in Developing Countries (Accepted for inclusion.). Aalborg.

Khan, M. S. H., Hasan, M., \& Clement, C. K. (2012). Barriers to the introduction of ICT into education in developing countries: The example of Bangladesh. International Journal of Instruction, 5(2), 61-80.

Larsson, J., \& Holmström, I. (2007). Phenomenographic or phenomenological analysis: does it matter? Examples from a study on anaesthesiologists' work. International Journal of Qualitative Studies on Health and Well-being, 2(1), 55-64. doi:10.1080/17482620601068105

Lashgarara, F. (2012). Effective factors on the villagers' use of rural telecentres (case study of Hamadan province, Iran). African Journal of Agricultural Research, 7(13), 2034-2041. doi:10.5897/AJAR11.2235

Mackenzie, N. \& Knipe, S. (2006). Research dilemmas: Paradigms, methods and methodology. Issues In Educational Research, 16(2), 193-205.

Marton, F. (1981). Phenomenography? Describing conceptions of the world around us. Instructional Science, 10(2), 177-200. doi:10.1007/BF00132516

Marton, F. (1997). Learning and awareness. Mahwah, NJ: Erlbaum Associates.

Oliver, D. G., Serovich, J. M., \& Mason, T. L. (2005). Constraints and Opportunities with Interview Transcription: Towards Reflection in Qualitative Research. Social Forces, 84(2), 1273-1289. doi:10.1353/sof.2006.0023

Pelgrum, W. . (2001). Obstacles to the integration of ICT in education: results from a worldwide educational assessment. Computers \& Education, 37(2), 163-178. doi:10.1016/S03601315(01)00045-8

Rogers, E. M. (1995). Diffusion of innovations (4th ed.). New York: Free Press. 
Rogers, P. L. (2000). Barriers to Adopting Emerging Technologies in Education. Journal of Educational Computing Research, 22(4), 455-472. doi:10.2190/4UJE-B6VW-A30N-MCE5

Sharma, R. C. (2003). Barriers in using technology for education in developing countries. In Proceedings. ITRE2003. International Conference (pp. 512-516). IEEE. doi:10.1109/ITRE.2003.1270670

Stake, R. E. (1995). The art of case study research. Thousand Oaks, NJ: Sage.

Teo, T. (2006). Attitudes toward computers: A study of post-secondary students in Singapore. Interactive Learning Environments, 14(1), 17-24. doi:10.1080/10494820600616406

Tezci, E. (2011). Turkish primary school teachers' perceptions of school culture regarding ICT integration. Educational Technology Research and Development, 59(3), 429-443. doi:10.1007/s11423-011-9205-6

Tondeur, J., van Keer, H., van Braak, J., \& Valcke, M. (2008). ICT integration in the classroom: Challenging the potential of a school policy. Computers \& Education, 51(1), 212-223. doi:10.1016/j.compedu.2007.05.003

Wachira, P., \& Keengwe, J. (2010). Technology Integration Barriers: Urban School Mathematics Teachers Perspectives. Journal of Science Education and Technology, 20(1), 17-25. doi:10.1007/s10956-010-9230-y

World Bank. (2012). Agriculture \& Rural Development | Data. Retrieved December 6, 2012, from http://data.worldbank.org/topic/agriculture-and-rural-development

Correspondence: Saifuddin Khalid, Ph.D. Candidate, Human Centered Communication and Informatics Program, Aalborg University, Aalborg, Denmark 